\title{
Hwang takes the stand at fraud trial
}

SEOUL

Woo Suk Hwang has taken the stand in court in his defence for the first time. The oncelauded cloning expert was confident and at times defiant as he struck back at the prosecution's claims that he embezzled money, committed fraud and broke a bioethics law, at one point citing dealings with the Russian mafia to explain himself.

Hwang electrified the scientific world in 2004 and 2005 with announcements that he had cloned human embryos and extracted stem cells with great therapeutic potential. But all the results were then shown to be fake. Hwang was charged in May with fraud, embezzlement of 2.8 billion won (US\$3 million) and violation of bioethics legislation

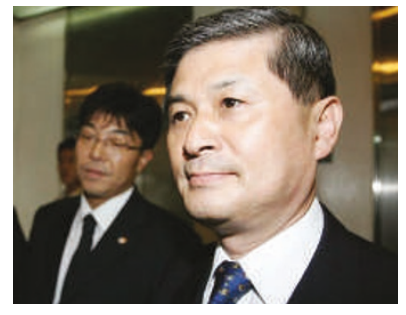

Woo Suk Hwang is in confident mood, despite serious allegations.
Prosecutors have struggled to track Hwang's expenses through at least 63 bank accounts carrying the names of members of his research team, a high-school classmate and a relative, as well as pig and cow dealers. Hwang first denied but later admitted using these accounts. According to the prosecutor's report, Hwang used to carry a bag full of cash to different bank branches, making relatively small deposits in various accounts minutes or hours apart.

The defence denies embezzlement, claiming that Hwang was not trying to fill his own coffers. Hwang's lawyers explained that money earmarked for buying cows and paying for junior lab members' housing was simply spent as part of overall research expenditures. that outlaws the purchase of eggs for research. Several of his colleagues were also charged with various offences.

Tracking Hwang's research funding has not been easy, and it is still not clear where all the money came from or where it ended up. For example, receipts for hundreds of millions of won for buying pigs and cows were faked.
"Hwang had no intention to make himself rich," says Keun-Hwa Jung, one of a team of at least five independent lawyers working on the case, pointing out that a tally of research spending shows that Hwang spent more than he received.

When he got the chance to put his side of the story, Hwang strode into court looking relaxed,

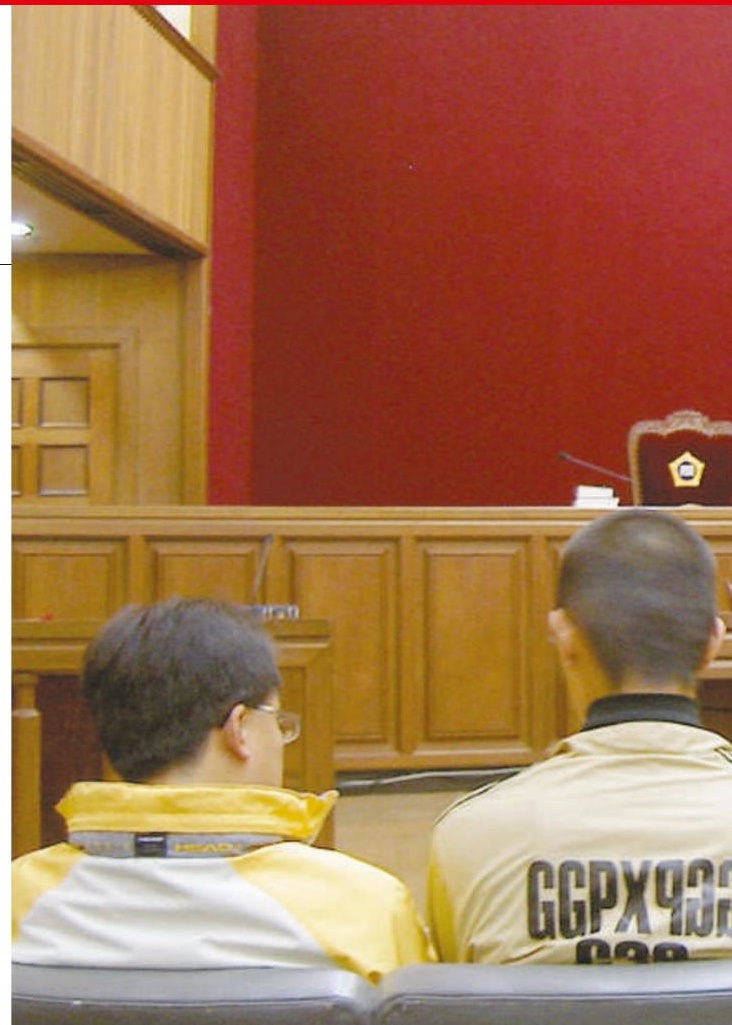

shaking hands with supporters. He explained some of the faked receipts by saying that he had given money to a Russian mafia group, as part of an effort to get tissue samples of a mammoth he was hoping to clone. He could not get receipts for those funds, Hwang told the court. The story is not as far-fetched as it might seem: there are ongoing mammoth-cloning projects in Japan. Hwang was keen to clone many different animals, including an endangered Korean tiger. And there is a black market for mammoth remains. Still, it is not clear how Hwang would have explained where he got the tissues if he had succeeded in creating a mammoth.

The lawyers also fended off the fraud allega-

\section{Safer embryo tests could boost IVF pregnancy rates}

\begin{abstract}
NEW ORLEANS
It may soon be possible to assess the health of an embryo created by in vitro fertilization (IVF) without interfering with a single cell on its future body. New assays that look for tell-tale molecules secreted by healthy embryos could help reproductive biologists select the embryos that are most likely to produce a baby.
\end{abstract}

In IVF, several embryos are usually created. Embryologists try to select the healthiest by visual inspection of the number of cells or the rate at which they divide, and transfer these back to the womb.

But these assessments are subjective and fallible. In the

\author{
United States, on average less \\ than $40 \%$ of IVF cycles end in \\ pregnancy. To improve the odds, \\ doctors routinely transfer multiple \\ embryos, increasing the risk of \\ twins or triplets. \\ Now researchers are working \\ on selection methods that are \\ quicker, more objective and \\ leave the embryo intact. Several \\ research groups and companies \\ presented preliminary studies \\ at the meeting of the American \\ Society for Reproductive Medicine \\ in New Orleans last week. \\ Such tests could boost \\ pregnancy rates as well as reduce \\ the need to transfer several \\ embryos and risk multiple births.
}

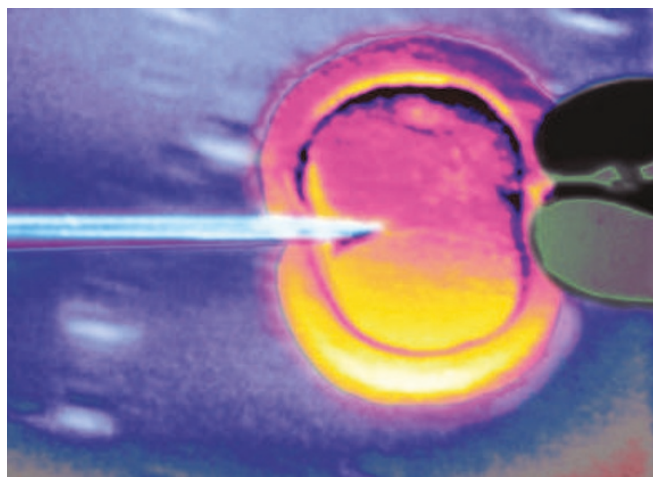

Select few: analysis of proteins secreted by embryos could provide more accurate healthy embryo selection in IVF treatment.
"Everyone's arriving at the same realization," says Dagan Wells, who studies gene expression in eggs at Yale University in New Haven, Connecticut.

Many groups are trying to find a fingerprint of proteins or metabolites that only healthy embryos secrete. Emre Seli at Yale and David Burns at McGill University in Montreal, Canada, have used spectroscopy to identify 


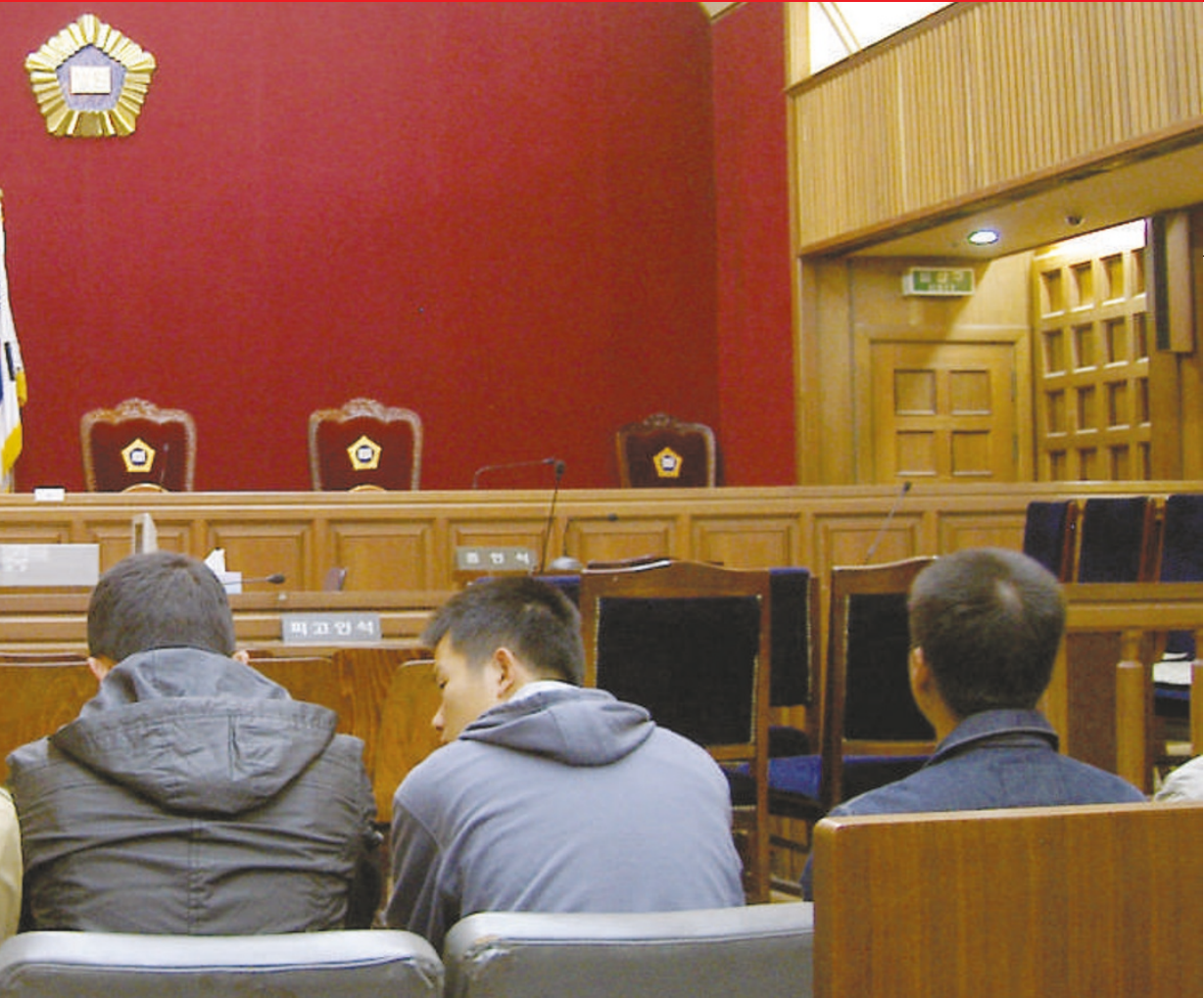

Courting support: Hwang's testimony struck back at prosecutors in front of a courtroom of supporters.

tions. The prosecution says that Hwang secured billions of Korean won from private companies using data that he knew to be faked. But Hwang claims he believed that at least some of the cell lines, including the original cell line presented in 2004, were real. Hwang admits ordering the fabrication of certain images, including slides of teratomas. The ability of stem-cell lines to form teratomas proves their ability to form virtually all types of body cells. But the tests take months, so when they did not work out, Hwang says he ordered faked photographs "to save time". He maintains, however, contrary to testimony by other researchers on the team, that he was not involved in any tests that would indicate he knew that the cell lines were fake, such as DNA fingerprinting tests that are necessary to match cell lines to the donor from which they are cloned. pared for the next hearing, which will deal with the allegation that Hwang violated the country's bioethics law when he used eggs from women who were given free IVF treatments in exchange for donating eggs. The law prohibits the provision of any "financial reward,
Hwang's lawyers already have their case pre-

property, or any other personal benefits" for the donation of sperm or eggs. But the lawyers will claim that illegal benefits do not include IVF treatment. "We have to rely on the spirit of the law here because the law itself is very unclear," says Jung.

Jung says that he hopes the judge will hand down a verdict by the end of the year. Hwang seems confident, and in anticipation of his acquittal has started up a new research institute in the outskirts of Seoul. One researcher there, who did not wish to be named without Hwang's approval, said he is very happy to be able to work with Hwang, which would have been unthinkable before. The institute is reportedly trying to clone pigs with humanized organs for transplantation, but the researcher refused to give any details.

If that happens, Hwang is likely to find support for his work. Some two hundred supporters attended the court to listen to Hwang's words, often nodding in solemn agreement. One was Zoon-hwan Go, a professor at Kyonggi University and author of a book, Entrapment, about a conspiracy against Hwang. "Hwang is diligent, truthful and pure," he told Nature during the trial. "I don't think he is perfectly clean," said another attendee. "But now everyone just thinks he's a liar. That's not right." She would be willing, she says, to donate eggs if Hwang were to start human research again.

Outside the courtroom, however, the country has mostly lost interest in the case. Many Koreans say it is an embarrassment they would like to forget.

David Cyranoski

such a signature in the media in which embryos are grown. Two trials reported at the meeting showed that the test could predict which embryos would implant with more than $70 \%$ accuracy. Seli says he will start recruiting women into a larger clinical trial within months.

Others are trying to assess eggs after they are collected but before fertilization. Selecting the most promising could allow fewer embryos to be created. This would be particularly useful in countries with legal restrictions such as Italy, where the law permits only three eggs at a time to be fertilized.

A group led by Samir Hamamah, who heads the assisted-reproduction unit at the Hôpital Arnaud de Villeneuve in Montpellier, France, is extracting and analysing the proteins in the cumulus cells that nestle intimately around an egg when it is ovulated. Hamamah reported in New Orleans that he has identified a handful of proteins that are manufactured at higher or lower levels in the cumulus cells of human eggs that go on to be fertilized compared with those that do not (S. Hamamah et al. RBM Online, www.rbmonline.com/ Article/2559).

Like any development in reproductive biology, such tests are unlikely to come without controversy. Some researchers claim that tests for an antigen called HLA-G in the growth medium of an embryo can predict the outcome of

IVF. But not everyone is convinced that its levels really correlate with pregnancy. Any new test should be shown to boost pregnancy rates in clinical trials before it is

\section{"Everyone's} arriving at the same realization." offered to patients says Mandy Katz-Jaffe at the Colorado Center for Reproductive

\section{Medicine in Englewood.}

Katz-Jaffe believes she can take such screening methods one step further. She is working on an ambitious test that will not only distinguish healthy embryos, but reveal whether or not an embryo carries a specific chromosomal abnormality.

At present, technicians can extract a cell from an embryo and test it for genetic defects, a procedure called preimplantation genetic diagnosis (PGD). But it's unclear whether this subtly damages the embryo. KatzJaffe is searching for proteins that are secreted at different levels by embryos with specific chromosomal defects, for example an extra copy of chromosome 21.

But Santigao Munne, an expert in PGD at diagnostic genetics company Reprogenetics in Livingston, New Jersey, questions whether this approach can replace PGD: "It's a lot of noise," he says. He believes that rather than detecting signs of particular abnormalities, such assays may simply be picking up molecules released by embryos that have stopped growing.

Helen Pearson 